\title{
Spontaneous Calcium Spike Activity in Embryonic Spinal Neurons Is Regulated by Developmental Expression of the $\mathrm{Na}^{+}, \mathrm{K}^{+}$-ATPase $\beta 3$ Subunit
}

\author{
Linda W. Chang ${ }^{1}$ and Nicholas C. Spitzer ${ }^{2}$ \\ ${ }^{1}$ Department of Bioengineering and ${ }^{2}$ Neurobiology Section, Division of Biological Sciences, Kavli Institute for Brain and Mind, University of California, San \\ Diego, La Jolla, California 92093-0357
}

\begin{abstract}
Different types and patterns of spontaneous electrical activity drive many aspects of neuronal differentiation. Neurons in the developing Xenopus spinal cord exhibit calcium spikes, which regulate gene transcription and neurotransmitter specification. The ionic currents necessary for spike production have been described. However, the mechanisms that generate the onset of this activity and the basis of its regulation remain unclear. Although signaling molecules appear to act on plasma membrane receptors to trigger calcium spike activity, other mechanisms for spontaneous calcium spike regulation may exist as well. Here, we analyze the developmental expression of the $\mathrm{Na}^{+}, \mathrm{K}^{+}$-ATPase $\beta 3$ subunit in Xenopus tropicalis embryos and show that its levels are downregulated at a time during embryonic development that coincides with the onset of prominent calcium spike activity in spinal neurons. Inhibition of an earlier increase in $\beta 3$ expression leads to more depolarized resting membrane potentials and results in later reduction of spike activity. This suppression of $\beta 3$ levels also reduces expression of the store-operated calcium channel subunit, Orail. These findings suggest that the $\mathrm{Na}^{+}, \mathrm{K}^{+}$-ATPase plays a role in initiating calcium spike activity and regulating calcium homeostasis.
\end{abstract}

\section{Introduction}

Calcium signals are vital for many processes during embryonic development. In the nervous system, fluctuations in intracellular calcium levels play important roles in proliferation, migration, and neuronal differentiation (Spitzer, 2006). Spontaneous calcium transients in embryonic Xenopus laevis spinal neurons have been shown to regulate processes including growth cone motility (Gomez and Spitzer, 1999; Gomez et al., 2001; Conklin et al., 2005; Sann et al., 2008), as well as potassium channel and neurotransmitter expression (Gu and Spitzer, 1995; Borodinsky et al., 2004).

Spontaneous calcium spikes in X. laevis are generated before synapse formation by long duration calcium-dependent action potentials that rely on depolarization-induced calcium influx from voltage-gated channels (Hayes and Roberts, 1973; Holliday and Spitzer, 1990; Gu et al., 1994). The ensuing calcium currents, resulting from activation of low-voltage-activated (LVA) and high-voltage-activated (HVA) calcium channels, trigger calciuminduced calcium release from intracellular stores (Holliday et al.,

Received Sept. 5, 2008; revised March 6, 2009; accepted March 31, 2009.

This work was supported by National Institutes of Health (NIH) Grant R01MH074702 (N.C.S.). We thank members of our laboratory for helpful discussions and technical assistance; D. Dulcis, K. Marek, and X. Nicol for comments on this manuscript; and I. Hsieh for technical support. We also acknowledge the Genomics Core at the University of California, San Diego Center for AIDS Research (Director, Dr. Christopher Woelk; NIH-National Institute of Allergy and Infectious Diseases Grant Al36214) and the San Diego Veterans Medical Research Foundation in this work.

Correspondence should be addressed to either Linda W. Chang or Nicholas C. Spitzer, Neurobiology Section Division of Biological Sciences, University of California, San Diego, 9500 Gilman Drive, La Jolla, CA 92093-0357. E-mail: Iwchang@ucsd.edu or nspitzer@ucsd.edu.

D01:10.1523/JNEUROSCI.4264-08.2009

Copyright $\odot 2009$ Society for Neuroscience $\quad$ 0270-6474/09/297877-09\$15.00/0
1991; Gu and Spitzer, 1993). During the period of calcium spiking, neurons have arrived near their mature positions in the spinal cord and are extending axons. As development progresses, increased expression of outward potassium currents gradually eliminates the calcium component of the action potential and synapses form (O’Dowd et al., 1988; Lockery and Spitzer, 1992). Although the currents necessary for driving calcium-dependent action potentials have been identified, the developmental events responsible for eliciting the period of increased spike activity remain undetermined. Temporal regulation of the $\mathrm{Na}^{+}, \mathrm{K}^{+}$ATPase $\beta 3$ subunit occurs during neurulation, suggesting a possible role for this subunit in neuronal differentiation (Good et al., 1990; Messenger and Warner, 2000). We have tested the hypothesis that appropriate developmental expression of the $\beta 3$ subunit is necessary to regulate the appearance of prominent calcium spike activity.

The $\mathrm{Na}^{+}, \mathrm{K}^{+}$-ATPase is a heteromeric electrogenic pump that requires both an $\alpha$ and $\beta$ subunit to produce a functional enzyme capable of ion transport. Four $\alpha$ and three $\beta$ isoforms have been characterized. The larger $\alpha$ subunit contains the binding sites for cations, ATP, and cardiac glycosides, whereas the $\beta$ subunit is important for pump assembly and plasma membrane insertion (Geering, 2001; Kaplan, 2002). Another tissue-specific subunit, $\gamma$, also modulates pump kinetics but is not crucial for $\alpha-\beta$ formation or $\alpha-\beta$ transport out of the endoplasmic reticulum (ER) (Béguin et al., 1997; Therien et al., 1997; Pu et al., 2002).

We find that Xenopus tropicalis neurons generate calcium spikes within a shorter developmental time window than the corresponding period of activity in X. laevis (Borodinsky et al., 2004). $\mathrm{Na}^{+}, \mathrm{K}^{+}$-ATPase $\beta 3$ subunit expression during develop- 
ment is also different between $X$. tropicalis and that reported for $X$. laevis (Messenger and Warner, 2000). A period of $\beta 3$ upregulation, followed by downregulation, immediately precedes the period of highest spontaneous calcium spike activity, suggesting that $\beta 3$ expression is important for triggering calcium spiking in $X$. tropicalis. The results of knocking down $\beta 3$ levels support this interesting role. Regulation of neural cell fate specification genes appears unaffected by $\beta 3$ reduction, but expression of the calcium store refilling channel, Orail, is downregulated. These results indicate that developmental regulation of the $\mathrm{Na}^{+}, \mathrm{K}^{+}$-ATPase $\beta 3$ subunit is necessary to promote the appearance of early electrical excitability.

\section{Materials and Methods}

Generation and staging of embryos. Adult Xenopus females were primed and injected with human chorionic gonadotropin (Sigma-Aldrich) to induce ovulation. X. laevis oocytes were fertilized in vitro, and X. tropicalis embryos were acquired either by natural mating or by in vitro fertilization. All embryos were grown at $21-23^{\circ} \mathrm{C}$ in $0.1 \times$ Marc's modified Ringer's solution (MMR) $(1 \times$ MMR contains $100 \mathrm{~mm} \mathrm{NaCl}, 2 \mathrm{~mm} \mathrm{KCl}$, $1 \mathrm{~mm} \mathrm{MgSO}_{4}, 5$ mм HEPES, 0.1 mм EDTA, $2 \mathrm{~mm} \mathrm{CaCl}_{2}$, pH adjusted to 7.8) and staged according to Nieuwkoop and Faber (1967).

Cell culture. Neuron-enriched cultures were prepared from the posterior neural plate of stage $15 \mathrm{X}$. laevis and X. tropicalis embryos as described previously (Gu et al., 1994), and cells were plated $1 \mathrm{~h}$ after initial dissection in $35 \mathrm{~mm}$ tissue culture-treated plastic dishes (Corning) with $2 \mathrm{ml}$ of modified Ringer's solution (MR) (116 mM NaCl, $0.67 \mathrm{~mm} \mathrm{KCl}$, $1.31 \mathrm{~mm} \mathrm{MgSO}_{4}, 2 \mathrm{~mm} \mathrm{CaCl}_{2}, 4.6 \mathrm{~mm}$ Tris base, $\mathrm{pH}$ adjusted to 7.8 ). Each dish contained cells from one embryo and all cultures were grown and imaged at room temperature $\left(21-23^{\circ} \mathrm{C}\right)$.

In vitro calcium imaging. Cultured cells were incubated in MR containing 1.25 $\mu \mathrm{M}$ Fluo-4 AM (Invitrogen), 0.01\% Pluronic F-127 (Invitrogen), and $0.2 \%$ DMSO (Sigma-Aldrich) for 50-60 min. Cells were washed three times after incubation and imaged in MR. Fluorescence images were acquired with a Bio-Rad MRC-600 argon laser confocal microscope (Bio-Rad) and analyzed with NIH Image 1.63 (W. Rasband, National Institutes of Health, Bethesda, MD; http://rsb.info.nih.gov/nihimage/). Young cultures ( $3 \mathrm{~h}$ in vitro) were imaged at $0.2 \mathrm{~Hz}$ for $0.5 \mathrm{~h}$ to minimize photodamage. Neurons were allowed to grow several hours after imaging to assess health and to verify neuronal identity after axonogenesis that generates phase-dark neurites with lengths $\geq 1 \times$ the cell body diameter. Cultures younger than $3 \mathrm{~h}$ in vitro could not be imaged because cells had not yet adhered to the substrate, precluding loading and washout of calcium indicator. Older cultures ( $\geq 4 \mathrm{~h}$ in vitro) were imaged at $0.2 \mathrm{~Hz}$ for $1 \mathrm{~h}$. Calcium spikes were identified by their rise time (within $5 \mathrm{~s}$ to peak) and amplitude ( $>2$ SDs from the baseline noise fluorescence). Although calcium spikes can occur in bursts, spike frequency was scored as the number of spikes per hour. Neurons that were inactive during the imaging period were not analyzed.

Embryo dissections for in vivo studies. Stage 15-26 embryos were dissected in wells of Sylgard-coated (Dow Corning) Petri dishes containing $1 \mathrm{mg} / \mathrm{ml}$ collagenase B (Roche). Briefly, the gut and epidermis surrounding the presumptive spinal cord were cut away, the endodermal yolk layer was removed, and embryos were secured to the Sylgard-lined wells ventral side up with 0.10-mm-diameter stainless-steel Austerlitz Minutien pins (Fine Science Tools). After pinning, the myotomes and notochord were gently removed with sharp forceps, and the solution was replaced with MR.

In vivo calcium imaging. Presumptive spinal cords were loaded with Fluo-4 AM according to Root et al. (2008). For KCl experiments, dissected stage 15 presumptive spinal cords were exposed to osmotically balanced $25 \mathrm{~mm} \mathrm{KCl}$ for $4-5 \mathrm{~h}$ before imaging and loaded with Fluo- 4 AM during the last hour of incubation. All imaging was performed in MR. Fluorescence images were acquired with a Leica SP5 confocal mi- croscope (Leica) and Bio-Rad MRC-600 or 1024 confocal microscopes at $21-23^{\circ} \mathrm{C}$ at an acquisition rate of $0.2 \mathrm{~Hz}$ for $0.5 \mathrm{~h}$ and analyzed with NIH Image. Calcium spikes were identified as described for in vitro imaging. The imaged field of view for each spinal cord contained 60-100 neurons. Spinal cords that did not exhibit activity and neurons that did not spike during the imaging period were excluded from analysis.

RNA isolation and cDNA synthesis. Total RNA was isolated from whole embryos ranging in development from early neurula to tailbud stages using the RNAqueous-4PCR kit (Ambion). The jelly coats and vitelline membrane of each embryo were removed with sharp forceps before RNA harvesting. RNA concentration and quality were determined by diluting samples in nuclease-free $\mathrm{H}_{2} \mathrm{O}$ and measuring the absorbance of each sample at 260 and $280 \mathrm{~nm}$. A total of $2.5 \mu \mathrm{g}$ of total RNA was then reverse-transcribed using the SuperScript III First-Strand Synthesis System for reverse transcription (RT)-PCR (Invitrogen) with oligo- $\mathrm{dT}_{20}$ primers. After reverse transcription, the cDNA was diluted and stored in frozen aliquots.

Quantitative RT-PCR. Selection of primers was performed with Primer3 (http://frodo.wi.mit.edu/cgi-bin/primer3/primer3_www.cgi) and cross-dimer formation was checked with NetPrimer (Premier Biosoft International). All primers listed in Table 1 were synthesized by Allele Biotech and used at a final concentration of $200 \mathrm{~nm}$ each. A total of $10 \mathrm{ng}$ of cDNA template were used per reaction. cDNA diluted from $11 \mathrm{em}-$ bryos was used for the $\mathrm{Na}^{+}, \mathrm{K}^{+}$-ATPase subunit assay per stage and candidate gene studies were performed with diluted cDNA from $5 \beta 3$ MO-treated and 5 untreated embryos per stage. Results were averaged for $n \geq 3$ individual runs from separate clutches of embryos. All reactions were run in triplicate on an ABI PRISM 7900HT Sequence Detection System (Applied Biosystems) with default settings for absolute quantitation using a standard curve and Power SYBR Green PCR Master Mix (Applied Biosystems).

Construction of plasmid DNA standards for quantitative RT-PCR. Regions of each gene examined were amplified by RT-PCR using Platinum TaqDNA Polymerase High Fidelity (Invitrogen) with the same primers used for quantitative RT-PCR (qRT-PCR). RT-PCR products were electrophoresed on a $2 \%$ agarose gel and purified with the QIAquick Gel Extraction kit (QIAGEN). Fragments were subsequently cloned into pCR2.1-TOPO vectors using the TOPO TA Cloning kit (Invitrogen) and the resulting plasmids amplified and purified. Samples were diluted in triplicate and optical density readings were averaged to determine final DNA concentration. Plasmids were then sequenced to verify that correct inserts were cloned, and each unique DNA standard was serially diluted and stored in aliquots at $-80^{\circ} \mathrm{C}$.

Morpholino design and blastomere injections. The splice-blocking $\mathrm{Na}^{+}$, $\mathrm{K}^{+}$-ATPase $\beta 3$ subunit lissaminated antisense morpholino oligonucleotide ( $\beta 3 \mathrm{MO}$ ) (5'-AAATGAATGATCGGCTTTCTCACCC-3') was directed to the first splice donor site of the $\beta 3$ primary RNA sequence and synthesized by GeneTools. The preliminary genomic sequence of the $\beta 3$ subunit was obtained by aligning the $\beta 3$ mRNA sequence to the JGI $X$. tropicalis genome assembly (version 4.1) using the BLAST alignment search tool to determine exon-intron boundaries. Splice junctions were confirmed by amplifying intron 1 of the $\beta 3$ gene with RT-PCR and sequencing the resulting product (Eton Bioscience). Primers used for intron amplification were located in exon 1 (5'-CAAGGAAGAGAACAAGGGAAGC- $\left.3^{\prime}\right)$ and exon 2 (5'-GGTATTTGGGGACAGAATCATC- $\left.3^{\prime}\right)$. To verify the identity of misspliced transcripts, primers pE1 (5'-AGAACAAGGGAAGCGAGCAG-3'), pI1 (5'-CAAAGCAAAGCAGACAGAGG$\left.3^{\prime}\right)$, and pE3 (5'-AAGCCCAGCAGATTTAGGAG-3') were used. A 
A

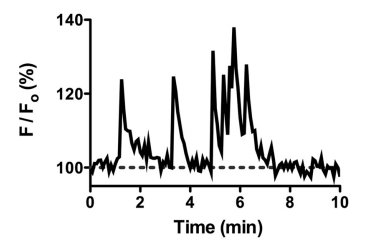

D

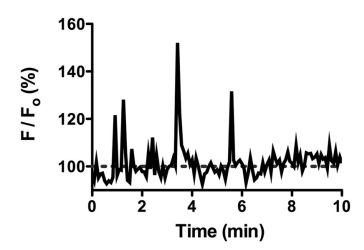

B

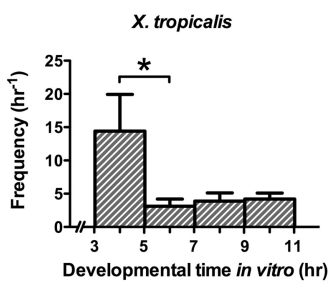

E

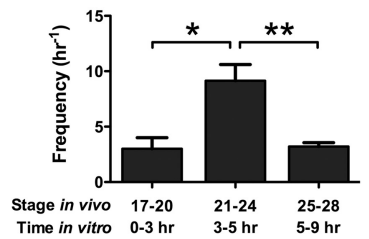

C

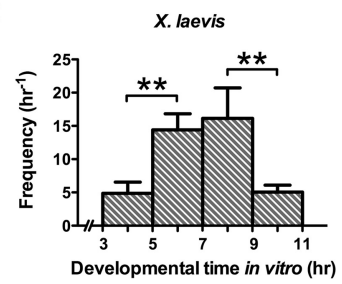

$\mathbf{F}$

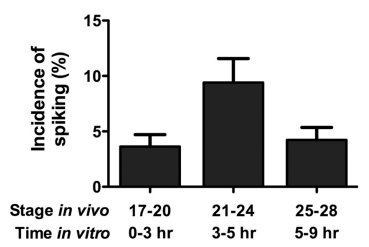

Figure 1. Embryonic amphibian spinal neurons exhibit spontaneous $\mathrm{Ca}^{2+}$ spike activity during growth in vitro and in vivo. $\boldsymbol{A}$ $\mathrm{Ca}^{2+}$ spike activity of $\mathrm{X}$. tropicalis neuron at $3 \mathrm{~h}$ in culture. Spikes are often generated in bursts. $B, C$, Distinct periods of increased spike activity occur during neuronal development in two different frog species. In X. tropicalis neurons in vitro, $\mathrm{Ca}^{2+}$ spike frequency is highest between 3 and $5 \mathrm{~h}$ of development. $\mathrm{Ca}^{2+}$ spike frequency of $X$. laevis neurons in vitro is highest between 5 and 9 h of development $\left({ }^{*} p<0.05,{ }^{* *} p<0.01 ; n=9-23\right.$ neurons/group from $>5$ cultures). $D, C^{2+}$ spike activity of a $X$. tropicalis neuron on the ventral surface of the spinal cord at stage $22 . \boldsymbol{E}, \mathrm{Ca}^{2+}$ spike activity is elevated in $X$. tropicalis neurons in vivo at the corresponding time of development in vitro. Neurons on the ventral surface of the spinal cord exhibit high frequencies of $\mathrm{Ca}^{2+}$ spiking between stages 21 and $24\left({ }^{*} p<0.05,{ }^{* *} p<0.01 ; n=3-10\right.$ embryos/stage). $\boldsymbol{F}$, The incidence of spiking on the ventral spinal cord is also high at these stages, although the variance prevents it from achieving significance. All values are means \pm SEM.

standard lissaminated control morpholino (CMO) (5'-CCTCTTACCTCAGTTACAATTTATA-3') (GeneTools), which does not target Xenopus genes was used as a negative control. For imaging and electrophysiology experiments, one blastomere of a two-cell stage embryo was injected with $10-20 \mathrm{ng}$ of $\beta 3 \mathrm{MO}$. For qRT-PCR, embryos were injected at the one-cell stage with 21-26 ng of $\beta 3 \mathrm{MO}$. Healthy embryos were transferred to Petri dishes containing $0.1 \times$ MMR after injections and incubated in the dark.

Electrophysiology. Intracellular recordings were made from ventral spinal neurons using sharp electrodes backfilled with $1 \mathrm{~m}$ potassium acetate. Stage 21/22 embryos were dissected, transferred to a Sylgard-lined recording chamber filled with MR, and pinned ventral side up at the rostral and caudal ends. Electrodes were pulled to have a resistance of 25-45 $\mathrm{M} \Omega$, and membrane potentials were measured in vivo within $1 \mathrm{~h}$ of dissection using an Axoclamp-2B amplifier (Molecular Devices) in bridge mode. Fresh saline was replaced every $20 \mathrm{~min}$. Experiments were blinded by identifying the $\beta 3 \mathrm{MO}$-treated side by fluorescence microscopy only after measurements were made.

Statistical analysis. Statistical analyses were performed using GraphPad Prism 5 (GraphPad Software). Calcium spike frequency and incidence were analyzed with Kruskal-Wallis tests followed by Dunn's post test and Mann-Whitney $U$ tests. All other data were analyzed with twotailed paired or unpaired $t$ tests unless otherwise indicated. Data are presented as means \pm SEM. Results are considered significant when $p<$ 0.05 .

\section{Results}

Calcium spikes in Xenopus embryonic spinal neurons in vitro Previous studies of calcium spike activity in embryonic amphibian neurons focused on neurons from the X. laevis spinal cord (Gu et al., 1994; Gu and Spitzer, 1995; Borodinsky et al., 2004). To determine the firing behavior of $X$. tropicalis spinal neurons, we first analyzed calcium spiking in vitro, and cultured neurons in $2 \mathrm{~mm}$ instead of $10 \mathrm{~mm}$ calcium medium because this more closely approximates the in vivo concentration of calcium ions. Neural ectoderms of $X$. tropicalis embryos were dissociated, plated, and allowed to develop in culture. Cells were loaded with the fluorescent calcium indicator dye Fluo-4 AM, and spike activity was assayed by confocal microscopy. Digitized traces of fluorescence levels in each neuron over time were analyzed and scored for spikes (Fig. 1A).

The average firing frequency of $X$. tropicalis neurons is highest between 3 and $5 \mathrm{~h}$ of growth in vitro. At these times, neurons spike at a rate of $14.4 \pm 5.5 \mathrm{~h}^{-1}$ (Fig. $1 B)$. During $5-7 \mathrm{~h}$, the frequency of calcium spikes declines to $3.1 \pm 1.1 \mathrm{~h}^{-1}$ and does not return to the high levels seen between 3 and $5 \mathrm{~h}$ at later time points (Kruskal-Wallis, $p<0.05$, followed by Dunn's post test, $p<0.05)$. We also analyzed spike activity in $X$. laevis spinal neurons grown in $2 \mathrm{~mm}$ calcium culture medium for comparison with neurons from $X$. tropicalis. Before $5 \mathrm{~h}$ of development, the average number of spikes recorded is $4.9 \pm 1.7 \mathrm{~h}^{-1}$. Between 5 and $7 \mathrm{~h}$, calcium spike frequency increases to $14.4 \pm 2.4$ $\mathrm{h}^{-1}$ and remains high $\left(16.1 \pm 4.6 \mathrm{~h}^{-1}\right)$ through 7-9 $\mathrm{h}$ of development in vitro (Fig. 1C). This developmental pattern parallels that previously described for these neurons when grown in $10 \mathrm{~mm}$ calcium culture medium (Gu and Spitzer, 1995). After $9 \mathrm{~h}$, the number of spikes recorded decreases to $5.0 \pm 1.0 \mathrm{~h}^{-1}$. The mean frequencies seen between $3-5$ and $9-11 \mathrm{~h}$ are significantly different from those seen during the 5-9 h time window (Kruskal-Wallis, $p<0.001$, followed by Dunn's post test, $p<0.01$ ). These results demonstrate that, although the average numbers of spikes recorded per hour in X. tropicalis and X. laevis neurons are comparable, the period of higher frequency calcium spiking in vitro appears earlier in $X$. tropicalis neurons than in X. laevis neurons.

\section{Calcium spikes in Xenopus embryonic spinal neurons in vivo}

The neuronal cultures consist of heterogeneous populations of cells from the spinal cord. Although neurons located on both dorsal and ventral surfaces spike in vivo in X. laevis, those positioned on the ventral surface spike at higher frequencies ( $\mathrm{Gu}$ et al., 1994; Borodinsky et al., 2004; Root et al., 2008). To analyze the window of calcium spike activity in $X$. tropicalis neurons in vivo, we thus considered the likelihood that ventral neurons constitute the majority of cultured neurons seen firing calcium spikes, and imaged the intact ventral spinal cord at stages that most closely coincide with in vitro development (Fig. 1D). Stages 21-24 encompass development between 3 and $5 \mathrm{~h}$ in vitro, and stages 25-28 coincide with development between 5 and $9 \mathrm{~h}$ in vitro. Since spike analysis of cultured neurons was not possible before $3 \mathrm{~h}$ in vitro, we also examined calcium spike activity at stages 17-20, which best correspond to these early time points.

Between stages 17 and 20, spinal neurons are rarely active and few spinal cords exhibit spike activity ( $n=3$ of 13 spinal cords). Nevertheless, active neurons fire calcium spikes at an average rate of $3.0 \pm 1.0 \mathrm{~h}^{-1}$. The mean spike frequency increases to $9.1 \pm 1.5$ $\mathrm{h}^{-1}$ between stages 21 and 24 and falls back down to $3.2 \pm 0.4$ $\mathrm{h}^{-1}$ between stages 25 and 28 (Kruskal-Wallis, $p<0.001$, followed by Dunn's post test, $p<0.05$ ) (Fig. $1 E$ ). These findings indicate that, in $X$. tropicalis, spike timing in vivo matches spike timing in vitro. The incidence of spiking seen in X. tropicalis spinal neurons during development in vivo parallels the trend seen for spike frequency. Between stages 17 and 20, the percentage of 


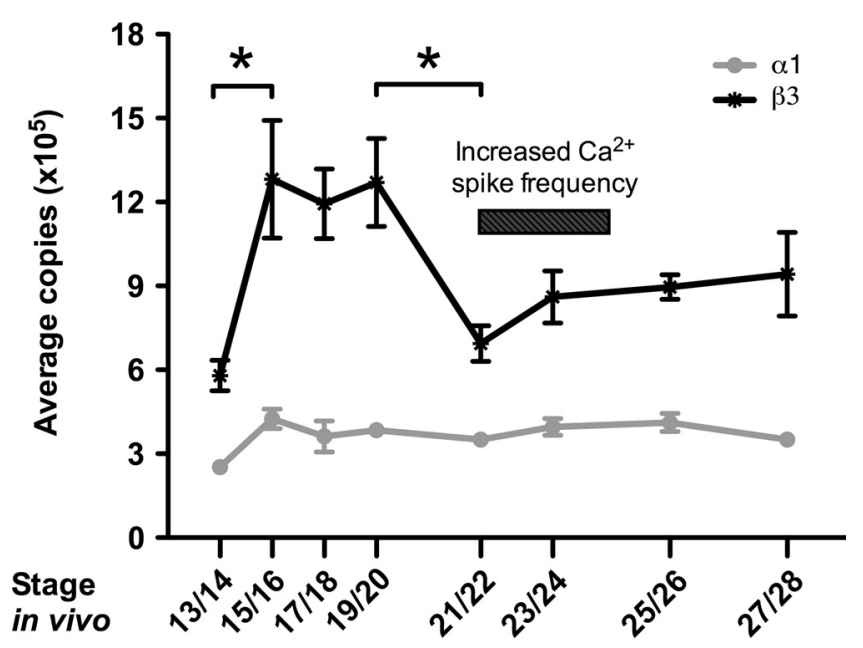

Figure 2. Temporal expression of $\mathrm{Na}^{+}, \mathrm{K}^{+}$-ATPase $\alpha 1$ and $\beta 3$ subunits in $X$. tropicalis embryos during development. Quantitative RT-PCR shows that $\beta 3$ mRNA transcript levels are significantly upregulated during development between stages 15 and 20, whereas no significant fluctuation of $\alpha 1 \mathrm{mRNA}$ transcript levels occurs between stages 15 and $28 . \beta 3$ transcript levels are downregulated at stage $21 / 22$, coinciding with the period of increased $\mathrm{Ca}^{2+}$ spiking observed both in vivo and in vitro $\left({ }^{*} p<0.05\right)$. Values are means \pm SEM for $n=4$ independent experiments.

spiking neurons in active spinal cords is $3.6 \pm 1.1 \% \mathrm{~h}^{-1}$. The incidence subsequently increases to $9.4 \pm 2.2 \% \mathrm{~h}^{-1}$ during stages 21-24 and declines to $4.2 \pm 1.1 \% \mathrm{~h}^{-1}$ between stages 25 and 28 (Fig. $1 F$ ). In X. laevis, the patterns of calcium spiking appear to be different. The duration of calcium spike activity in vivo is longer in $X$. laevis than in X. tropicalis [compare Fig. $1 E$ and Borodinsky et al. (2004), their Fig. 1f], and incidence and frequency trends across stages are not as well correlated (Borodinsky et al., 2004).

\section{Developmental regulation of $\mathrm{Na}^{+}, \mathrm{K}^{+}$-ATPase subunits}

Sodium pump activity is required for neuronal differentiation of $X$. laevis neurons in vitro (Messenger and Warner, 1979). The $\mathrm{Na}^{+}, \mathrm{K}^{+}$-ATPase in embryonic $X$. laevis is composed of $\alpha 1, \beta 1$, $\beta 2, \beta 3$, and $\gamma$ subunits (Good et al., 1990; Davies et al., 1996; Messenger and Warner, 2000; Eid and Brändli, 2001). Although the $\alpha 1$ subunit is present in a variety of structures including the neural plate (Davies et al., 1996), only $\beta 3$ of the known $\beta$ isoforms is expressed in the developing spinal cord, and the $\gamma$ subunit is not detected (Eid and Brändli, 2001). Therefore, we assayed $\alpha 1$ and $\beta 3$ transcript levels with qRT-PCR from the onset of neurulation through the tailbud stages of developing $X$. tropicalis embryos to determine whether developmental changes in $\mathrm{Na}^{+}$, $\mathrm{K}^{+}$-ATPase expression would overlap temporally with calcium spike activity.

$\alpha 1$ transcripts are expressed at relatively low levels at stage $13 / 14$. An increase of $\sim 70 \%$ occurs by stage $15 / 16$, and these transcript levels are maintained through stage 28 (Fig. 2). Similarly, $\beta 3$ levels are also relatively low at stage $13 / 14$ and significantly increase by $\sim 100 \%$ at stage $15 / 16$. Unlike $\alpha 1, \beta 3$ transcripts remain high through stage $19 / 20$ and then decrease significantly at stage $21 / 22$ to levels comparable with those observed at stage $13 / 14$ (one-way ANOVA, $p=0.0027$, followed by Newman-Keuls post hoc test, $p<0.05$ ). A slight increase in $\beta 3$ occurs beginning at stage $23 / 24$ and transcripts are sustained at this level through stage 28 . At all stages examined, $\beta 3$ transcripts are present in higher amounts than $\alpha 1$ transcripts. Similar observations have been made in several developing rat tissues (Orlowski and Lingrel, 1988), rat skeletal muscle (Lavoie et al., 1997), and mammalian kidney cell lines, and may be attributed to the more rapid degradation rate of the $\beta$ subunit compared with the $\alpha$ subunit (Mircheff et al., 1992; Lescale-Matys et al., 1993).

\section{Knockdown of $\beta 3$ subunit expression alters neuronal membrane potential}

These results indicate that upregulation and later downregulation of $\beta 3$ transcripts occurs during two distinct periods of development: neurulation and the appearance of calcium spike activity. The upregulation of $\beta 3$ between stages 15 and 20 during neural tube formation corresponds to a previously reported hyperpolarization of the membrane potential in neural plate cells during nervous system development (Blackshaw and Warner, 1976), and the timing of $\beta 3$ downregulation at stage $21 / 22$ is closely linked to the onset of increased calcium spike activity (Fig. $1 E, F)$. To address whether upregulation and subsequent downregulation of the sodium pump is necessary for the appearance of these calcium spikes, a splice-blocking morpholino was used to knock down $\beta 3$ expression.

To confirm the efficacy of the $\beta 3 \mathrm{MO}$, multiplex RT-PCR was performed on cDNA from stage $15 / 16$ control uninjected, CMOand $\beta 3 \mathrm{MO}$-injected embryos using primers designed to exon 1 , intron 1, and exon 3 (Fig. 3A). Two different sized PCR fragments were anticipated. The first corresponds to the correctly spliced wild-type $\beta 3$ mRNA that produces normal $\beta 3$ protein (Fig. $3 B$, top). The second corresponds to a misspliced $\beta 3$ transcript that retains the first intron. This variant of $\beta 3$ should cause a frameshift mutation that prematurely truncates the protein after translation of the first exon (Fig. 3B, bottom). RT-PCR amplifies a single band in both control and CMO-treated embryos (Fig. $3 C$ ), as expected for the correctly spliced $\beta 3$ transcript. In $\beta 3 \mathrm{MO}-$ treated embryos, a larger product corresponding to the intronretaining transcript is amplified in addition to the wild-type fragment. Sequencing of the amplicons confirmed the identity of the wild-type band and the aberrantly spliced $\beta 3$ product. Incomplete knockdown was essential to the study since knocking out various pump subunits during development is lethal (Magyar et al., 1994; James et al., 1999; Ikeda et al., 2003, 2004; Madan et al., 2007).

Embryos injected with the $\beta 3 \mathrm{MO}$ did not look morphologically different from control or CMO-injected embryos at the stages examined. However, $\beta 3 \mathrm{MO}$-treated embryos remained immobile and unresponsive when touched with a glass probe between late tailbud through larval stages, in contrast to controls that rapidly swam away. This paralysis was observed in $>95 \%$ of embryos treated with the $\beta 3 \mathrm{MO}$ but was not apparent in either control or CMO-treated embryos (data not shown).

Reducing $\beta 3$ expression should decrease $\mathrm{Na}^{+}, \mathrm{K}^{+}$-ATPase activity and consequently affect the membrane potential of developing neurons. Accordingly, we measured the resting membrane potential of ventral spinal neurons in unilaterally $\beta 3 \mathrm{MO}-$ treated embryos to quantify the knockdown (Fig. 3D). Neurons on the control side display an average membrane potential of $-36.5 \pm 1.6 \mathrm{mV}$. Decreasing $\beta 3$ levels raises the resting potential to $-19.6 \pm 1.6 \mathrm{mV}$, which is significantly different from controls, demonstrating that neurons on the $\beta 3 \mathrm{MO}$-injected side have more depolarized resting membrane potentials than those on the control side (two-tailed unpaired $t$ test, $p<0.0001$ ).

\section{Knockdown of $\beta 3$ subunit expression reduces calcium spiking}

Unilaterally $\beta 3 \mathrm{MO}$-treated spinal cords were also loaded with Fluo-4 AM between stages 17 and 24 and imaged to establish 
A

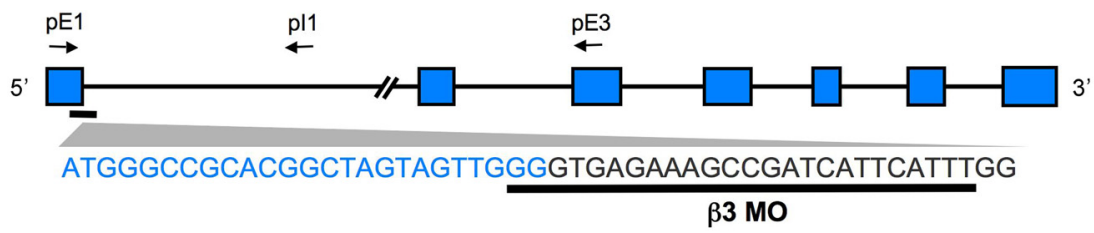

B
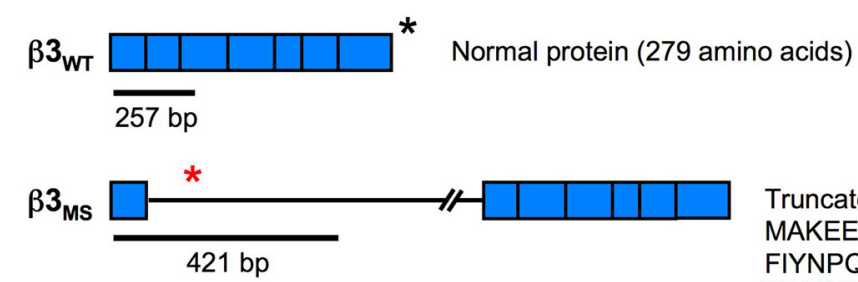

Truncated protein MAKEENKGSEQSGSDWKQ FIYNPQSGEFMGRTASSW GEKADHSFGDSGRGETGV* (54 amino acids)
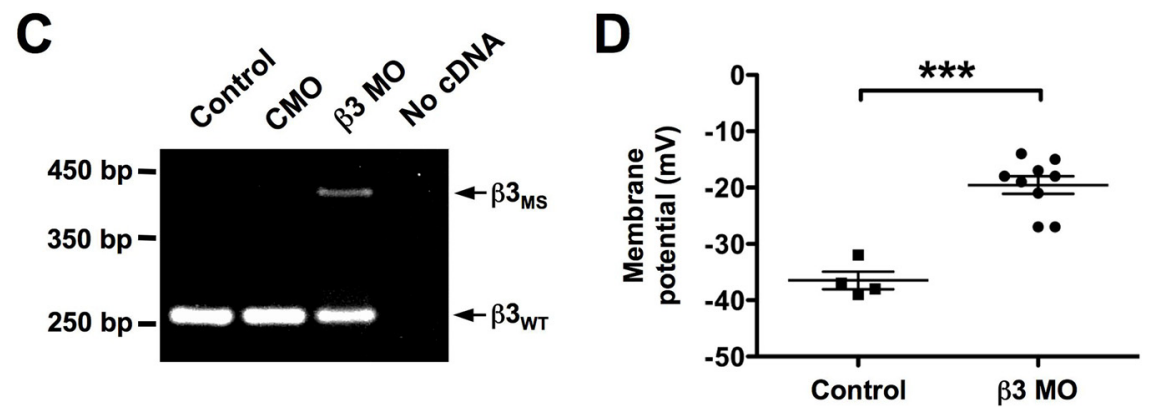

Figure 3. A splice-blocking morpholino ( $\beta 3 \mathrm{M} 0)$ disrupts normal splicing of the $\mathrm{Na}^{+}, \mathrm{K}^{+}$-ATPase $\beta 3$ subunit in $X$. tropicalis and alters the membrane potential of embryonic spinal neurons. $A$, Schematic of $\beta 3$ unspliced RNA and the $\beta 3 \mathrm{MO}$ target sequence. The blue boxes indicate exons, connecting lines represent introns, and arrows show approximate locations of primers used for RT-PCR. $\boldsymbol{B}$, Predicted splicing of $\beta 3 \mathrm{mRNA}$ in wild-type embryos and embryos after $\beta 3 \mathrm{M} 0$ treatment. Primers shown in $A$ amplify a 257 bp fragment in wild-type $\beta 3$ mRNA ( $\beta 3_{\text {WT }}$ ) (top) and a 421 bp fragment in misspliced $\beta 3$ mRNA ( $\beta 3_{\text {MS }}$ ) (bottom). $\beta 3_{\text {WT }}$ generates a 279 aa protein, whereas conceptual translation of the predicted $\beta 3_{\text {MS }}$ produces a 54 aa protein. The last 18 aa of this truncated protein (red text) are translated from the first intron. The asterisks represent the stop codon location in each transcript. C, RT-PCR of stage 15/16 $\beta 3$ M0-treated embryos using primers shown in $\boldsymbol{A}$ yields predicted spliced and misspliced products schematized in $\boldsymbol{B}$. Control uninjected and CM0-treated embryos do not produce the $\beta 3_{\mathrm{MS}}$ transcript. $\boldsymbol{D}$, Intracellular recordings of stage $21 / 22$ ventral spinal neurons from embryos injected with $\beta 3 \mathrm{MO}$ in one blastomere at the two-cell stage. Neurons on the $\beta 3 \mathrm{MO}$-treated side display significantly more depolarized membrane potentials than neurons on the control side $\left({ }^{* * *} p<0.0001\right)$. Each point represents a recording from a single neuron. The horizontal lines represent the mean \pm SEM.

whether $\mathrm{Na}^{+}, \mathrm{K}^{+}$-ATPase expression plays a role in regulating calcium spike activity (Fig. $4 A$ ). The one-half of the spinal cord treated with the lissaminated $\beta 3 \mathrm{MO}$ was identified by red fluorescence (Fig. $4 B$ ) and the merged image revealed that spiking neurons were predominantly located on the contralateral control side (Fig. 4C). Before neural tube closure (stages 17-20), $1.2 \pm$ $0.7 \%$ of neurons spike per hour on the $\beta 3 \mathrm{MO}$-treated side, whereas $3.5 \pm 1.4 \%$ of neurons spike per hour on the control side (Mann-Whitney $U$ test, $p>0.18$ ) (Fig. $4 D$ ). In contrast, the incidence of spiking neurons on the control side is $11.8 \pm 1.9 \%$ $\mathrm{h}^{-1}$ during stages $21-24$. When $\beta 3$ is knocked down, the percentage of active neurons drops to $0.6 \pm 0.4 \% \mathrm{~h}^{-1}$ (Mann-Whitney $U$ test, $p<0.0001)$. The significant change in incidence between $\beta 3 \mathrm{MO}$-treated and untreated embryos during stages $21-24$, but not $17-20$, indicates that $\beta 3$ expression is necessary between stages 17 and 20 for the initiation of calcium spike activity.

Spike frequencies in control and $\beta 3 \mathrm{MO}$-treated neurons also follow similar trends. During stages $17-20$, neurons on the $\beta 3$ MO-treated side of the spinal cord fire spikes at a rate of only 2 $\mathrm{h}^{-1}$, which does not differ significantly from the control side frequency of $3.0 \pm 1.0 \mathrm{~h}^{-1}$. Between stages 21 and $24, \beta 3$ knockdown reduces the mean spiking rate to $3.2 \pm 0.8 \mathrm{~h}^{-1}$. This is significantly lower than the average spike frequency seen on the control side (14.4 \pm $\left.1.8 \mathrm{~h}^{-1}\right)($ Mann-Whitney $U$ test, $p<0.05)$ (Fig. 4E).

Because $\beta 3$ MO treatment causes depolarization of neurons, we determined whether a similar effect on calcium spiking is produced by sustained depolarization with $25 \mathrm{~mm} \mathrm{KCl}$. Higher concentrations of $\mathrm{KCl}$ caused isolated spinal cords to dissociate gradually during the $4-5 \mathrm{~h}$ incubation period encompassing stages $15-20$, precluding calcium imaging. Spike incidence and frequency were normal when $\mathrm{KCl}$ was not applied $\left(12.1 \pm 2.6 \% \mathrm{~h}^{-1}\right.$; $14.2 \pm 1.6 \mathrm{~h}^{-1} ; n=60$ neurons from six embryos), and abolished when $\mathrm{KCl}$ was applied and not washed out (data not shown). Prolonged application of $25 \mathrm{~mm}$ $\mathrm{KCl}$ followed by washout reduced both the incidence and frequency of spiking $(6.5 \pm$ $0.6 \% \mathrm{~h}^{-1} ; 8.7 \pm 1.1 \mathrm{~h}^{-1} ; n=51$ neurons from eight embryos) (Fig. 5). These results indicate that the effect of chronic depolarization parallels the effect of $\beta 3 \mathrm{MO}$ treatment.

\section{$\mathrm{Na}^{+}, \mathrm{K}^{+}$-ATPase activity and gene expression}

Neuronal calcium signals use calcium influx from voltage-gated channels located in the plasma membrane as well as calcium released from intracellular ER stores (Berridge, 1998); both are required to generate calcium spike activity (Holliday and Spitzer, 1990; Holliday et al., 1991; Gu et al., 1994). The mechanisms of calcium release from stores involving activity of inositol triphosphate and ryanodine receptors are well described (Berridge, 1998). In comparison, less is known about the mechanisms of storeoperated calcium entry (SOCE) and store-operated calcium channels (SOCs), which replenish depleted stores. The most notable SOC is the calcium release-activated calcium (CRAC) channel. CRAC modulator 1 (Orail) constitutes the pore-forming subunit of the CRAC channel and is activated by the ER calcium sensor STIM1 (Feske et al., 2006; Prakriya et al., 2006; Soboloff et al., 2006; Vig et al., 2006; Yeromin et al., 2006; Lewis, 2007). Although SOCs and SOCE have been studied primarily in inexcitable cells, evidence now suggests that SOCE is also present in neurons (Bouron, 2000; Emptage et al., 2001; Tobin et al., 2006).

It was recently shown that Orail may have functions in the developing nervous system (Koizumi et al., 2007). To determine whether this gene is also present in embryonic $X$. tropicalis and whether knockdown of $\beta 3$ affects its expression, we performed qRT-PCR to evaluate Orail levels. We grouped the results according to developmentally significant events between stages 15 and 28: upregulation of $\beta 3$ expression (stages 15-20), increased calcium spike activity (stages 21-24), and the period after increased calcium spike activity (stages 25-28). In wild-type em- 
bryos, Orail transcripts are present throughout stages $15-20$ and increase $\sim 25 \%$ during development between stages 15-20 and 21-24 (Fig. 6A). Transcripts then remain at this elevated level through stage 28 . When $\beta 3$ is knocked down, Orail expression decreases concomitantly. At stages 15-20 and 21-24, transcript levels fall 25 and $35 \%$, respectively, from levels seen in wild-type embryos. Orail transcripts then increase slightly from stages 21-24 to stages 25-28, although levels are still significantly lower than those seen in wild-type embryos (two-tailed paired $t$ test, $p<0.05$ ).

We also investigated whether modulation of $\mathrm{Na}^{+}, \mathrm{K}^{+}$-ATPase activity affects expression of genes known to be involved in neural differentiation. Transcript levels of Notch homolog 1 (Notch1), oligodendrocyte transcription factor 2 (Olig2), and oligodendrocyte transcription factor 4 (Olig4) were examined in both treated and untreated embryos. These genes were chosen as controls for the $\beta 3 \mathrm{MO}$ treatment. Notch signaling plays roles in cell fate determination including the maintenance of neuronal progenitors and neuronal and glial differentiation (Louvi and Artavanis-Tsakonas, 2006; Shimojo et al., 2008), whereas the olig genes are basic helix-loophelix transcription factors thought to be important for oligodendrocyte development. Olig2 is located on the ventral surface of the spinal cord and is required to maintain motoneuron and oligodendrocyte precursors (Kessaris et al., 2001; Zhou et al., 2001; Lu et al., 2002; Zhou and Anderson, 2002; Rowitch, 2004). The less well characterized Olig4 is localized to the dorsal spinal cord and to date has only been found in the genomes of fish and amphibians (Bronchain et al., 2007). Nonetheless, its expression seems to be necessary for the differentiation of interneurons and astrocytes (Filippi et al., 2005; Bronchain et al., 2007).

A small decrease in the number of Notch 1 transcripts occurs between stages 21 and 24 in wild-type embryos. However, this is not significantly different from the levels seen at stages $15-20$ or stages 25-28. Likewise, no noticeable change in transcript levels is apparent between stages 15 and 28 among wild-type and $\beta 3 \mathrm{MO}$ treated embryos (Fig. $6 \mathrm{~B}$ ). The differences in olig gene expression among wild-type and $\beta 3 \mathrm{MO}$-treated embryos are also insignificant. Olig2 transcript levels remain stable throughout the stages examined and Olig4 levels steadily decline during development (Fig. 6C,D). Thus, whereas Orail expression is markedly decreased by $\beta 3$ knockdown, Notch1, Olig2, and Olig4 expression are not affected.

\section{Discussion}

Determining the level of sodium pump expression during early neuronal development is critical to understanding its role in driving spontaneous calcium spiking. The $\mathrm{Na}^{+}, \mathrm{K}^{+}$-ATPase directly affects the ionic gradients that maintain resting membrane potentials, which influence the activation of voltage-gated channels. In embryonic $X$. tropicalis, neuronal calcium spikes occur within a window of development after neural tube closure but before the formation of fully functional neuronal networks. Expression of the $\mathrm{Na}^{+}, \mathrm{K}^{+}$-ATPase $\beta 3$ subunit is upregulated during neurula-

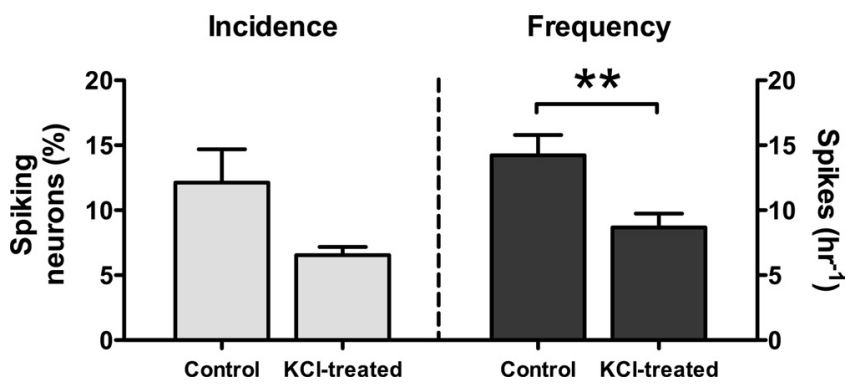

Figure 5. $\mathrm{Ca}^{2+}$ imaging of ventral spinal neurons in $\mathrm{KCl}$-treated embryos. The incidence of calcium spiking in presumptive spinal cords dissected at stage 15 and treated with $25 \mathrm{~mm} \mathrm{KCl}$ is lower than the incidence in controls. The frequency of calcium spiking in these $\mathrm{KCl}$-treated spinal cords is also less than the frequency in controls $\left({ }^{* *} p<0.01\right)$. Values are means \pm SEM for $n=6-8$ embryos/condition.

tion and downregulated at the time calcium spikes appear. Suppressing expression of $\beta 3$ shifts membrane potentials to more depolarized values and inhibits the appearance of spontaneous calcium spikes. Depolarization of the membrane potential with $\mathrm{KCl}$ produces a similar effect. These results support a model that requires activation of the $\mathrm{Na}^{+}, \mathrm{K}^{+}$-ATPase to initiate the cascade of events necessary for spike production (Fig. 7).

\section{$\boldsymbol{\beta} 3$ regulation and calcium channel activity}

Developmentally regulated $\beta 3$ expression is required for the appearance of calcium spikes, linking $\mathrm{Na}^{+}, \mathrm{K}^{+}$-ATPase activity with calcium signaling. However, the mechanism by which increased $\beta 3$ expression leads to activation of calcium channels necessary for spike production is unknown. We suggest that the activity of the $\mathrm{Na}^{+}, \mathrm{K}^{+}$-ATPase before neural tube formation removes sustained inactivation of LVA calcium channels, by hyperpolarizing the membrane potential. Additionally, it may facilitate channel insertion into the membrane. 

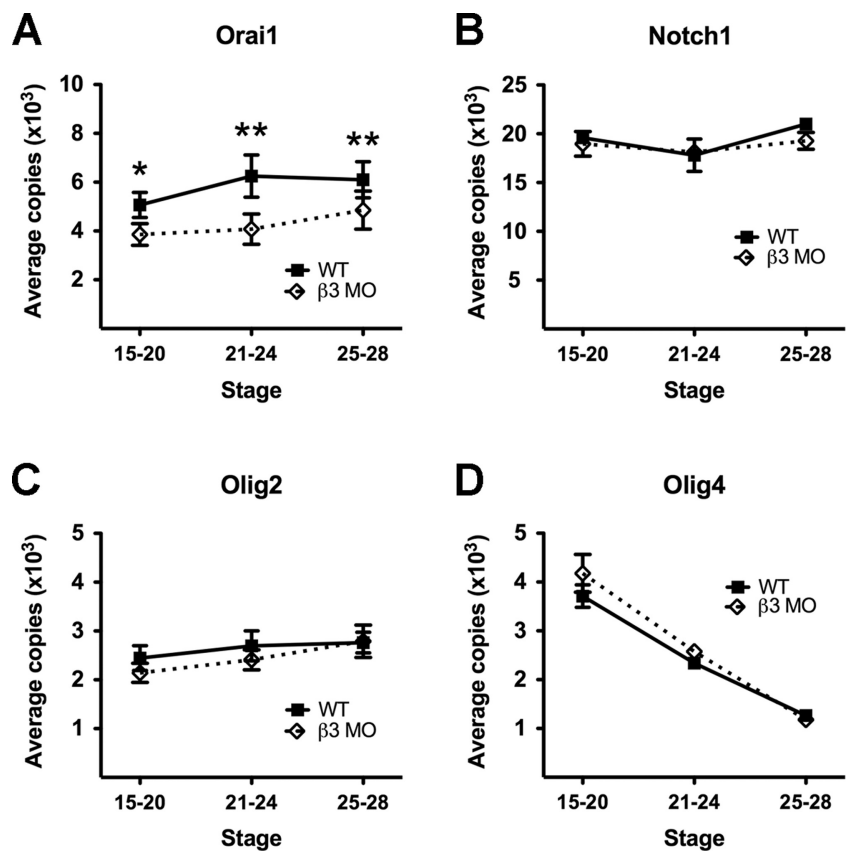

Figure 6. Decreased sodium pump expression reduces Orail gene expression during embryonic development. $\boldsymbol{A}$, When $\beta 3$ levels are knocked down, transcript levels of Orai1 are significantly reduced between stages 15 and $28\left({ }^{*} p<0.05,{ }^{* *} p<0.01\right)$. Decreased $\beta 3$ levels do not cause significant changes in Notch $1(\boldsymbol{B})$, Olig2 ( $\boldsymbol{C}$, and Olig4 (D) transcripts at the stages examined. All values are means \pm SEM for $n \geq 3$ independent experiments.

LVA T-type calcium currents appear early in neuronal development before HVA N- and L-type calcium currents in several neuronal populations, including mammalian hippocampal neurons (Yaari et al., 1987), chick sensory dorsal root ganglia (Gottmann et al., 1988), and chick motoneurons (McCobb et al., 1989). LVA currents are also activated at much lower thresholds than HVA currents and are present in embryonic X. laevis spinal neurons (Desarmenien et al., 1993; Gu and Spitzer, 1993). The importance of LVA current for calcium spike activity has been demonstrated in these neurons in vitro. Blocking this current eliminates calcium spike activity as effectively as inhibiting HVA current, indicating a role for LVA current in activating HVA currents ( $\mathrm{Gu}$ and Spitzer, 1993). The average resting membrane potential obtained when $\beta 3$ expression levels are decreased is substantially more positive than the voltage at which neuronal $\mathrm{T}$ current is completely inactivated in cultured X. laevis spinal neurons, suggesting that the failure of spike generation could be attributable to inactivation of LVA current. This would then prevent HVA activation and calcium-induced calcium release. It is also possible that failure to activate LVA current prevents HVA channel expression. Blocking T-type calcium channel activity early in development inhibits subsequent HVA calcium channel expression in NG108-15 neuroblastoma-glioma cells that are able to recapitulate well characterized neuronal properties (Chemin et al., 2002). However, whether this occurs in Xenopus spinal neurons has yet to be determined.

In addition, we find that knocking down $\beta 3$ expression decreases the transcription of Orail, which encodes a pore-forming subunit of a store-operated calcium channel. This suggests that there may be a decreased number of SOCs present in the plasma membrane, leading to a reduction in store refilling. Because spike amplitudes range in size and are mostly dependent on intracellular calcium stores (Holliday et al., 1991), the reduction in calcium levels will lead to an elimination of small spikes and a consequent reduction in overall spike frequency. The expression levels of other components regulating calcium spiking may change as well. These include ion channels that can raise the threshold for action potential initiation, further reducing the frequency and appearance of calcium spikes.

\section{$\beta 3$ regulation and neuronal differentiation}

Differentiation of cultured embryonic X. laevis neurons is inhibited when sodium pump activity is blocked during neurulation by strophanthidin, a cardiac glycoside that reversibly binds to the $\mathrm{Na}^{+}, \mathrm{K}^{+}$-ATPase (Messenger and Warner, 1979). To determine whether the lack of calcium spike activity could be attributed to failure of neurons to differentiate from precursors or to respecification of neurons to other cell types, we examined the expression levels of three genes involved in regulating neuronal and glial differentiation: Notch1, Olig2, and Olig4. No significant changes in any of these transcripts were observed as a result of $\beta 3$ knockdown.

Downregulation of Notch transcripts has been reported after strophanthidin treatment during neurulation (Messenger and Warner, 2000), which may have resulted either from species variation or from the severity of the knockdown strategy used. The morpholino concentrations used here may have inhibited pump activity to a lesser extent and certainly caused far fewer abnormal phenotypes than the strophanthidin concentrations used in previous studies (Messenger and Warner, 1979; Messenger and Warner, 2000). However, our findings suggest that the $\beta 3 \mathrm{MO}$ treatment was effective in reducing $\mathrm{Na}^{+}, \mathrm{K}^{+}$-ATPase expression. When $\beta 3$ levels are reduced, the membrane potential of ventral neurons becomes more depolarized compared with control neurons, consistent with reduced $\mathrm{Na}^{+}, \mathrm{K}^{+}$-ATPase activity. Moreover, a paralyzed phenotype is seen with the $\beta 3$ knockdown embryos, resembling that observed in animals with abnormal $\alpha$ subunit expression in other systems. Newborn mice lacking the $\alpha 2$ isoform exhibit no motor activity and die shortly after birth from lack of respiratory activity even though they have beating hearts (Moseley et al., 2003), whereas a mutation in the sole Drosophila $\alpha$ subunit causes bang-sensitive paralysis that is phenocopied in wild-type flies injected with ouabain (Schubiger et al., 1994). Our results provide a mechanistic understanding of the observation that pump activity is necessary for some aspects of development (Messenger and Warner, 1979, 2000; Breckenridge and Warner, 1982; Rowe et al., 1993), by providing a link between membrane potential and calcium spikes.

\section{Other modes of calcium spike regulation}

Recent work has shown that GABA and glutamate released at early stages of development bind to metabotropic receptors and regulate calcium spike activity in $X$. laevis. When these receptors are blocked, the incidence of spiking neurons decreases, suggesting that these neurotransmitters modulate spike activity (Root et al., 2008). In contrast, our findings identify a different mechanism regulating the onset of calcium spike activity in $X$. tropicalis. One possibility is that different neuronal populations use different mechanisms for generating calcium spikes, since blocking metabotropic receptors with pharmacological antagonists only prevents a subpopulation of neurons from spiking (Root et al., 2008). Another possibility is that neurons use different machinery to initiate the period of calcium spiking in different species or at different times during this period in both species. It would be interesting to determine whether reducing sodium pump activity alters GABA and glutamate expression in the developing spinal cord before the onset of activity, and whether the two mecha- 
nisms are linked. Reducing sodium pump activity during early neuronal development could prevent calcium channel expression or activation, which would then preclude effects of neurotransmitter receptor activation on calcium spike activity. Alternatively, the intracellular signaling cascades activated by these metabotropic receptors could impact $\mathrm{Na}^{+}, \mathrm{K}^{+}$-ATPase function and provide a feedback mechanism with which to regulate calcium spiking.

\section{Adhesive roles of $\boldsymbol{\beta}$ subunits}

Other $\mathrm{Na}^{+}, \mathrm{K}^{+}$-ATPase $\beta$ subunits have adhesive roles in addition to facilitating ion transport. The $\mathrm{Na}^{+}, \mathrm{K}^{+}$-ATPase $\beta 2$ subunit functions as an adhesion molecule on murine glia, where it is involved in neuron-astrocyte adhesion and promotes neurite outgrowth in a calciumindependent manner (Antonicek et al., 1987; Gloor et al., 1990; Müller-Husmann et al., 1993). The $\beta 1$ subunit also has roles in cell-cell adhesion and the formation of trophectoderm tight junctions (Shoshani et al., 2005; Vagin et al., 2006; Madan et al., 2007). This role appears to be shared among $\beta$ subunit isoforms of voltage-gated sodium channels as well; their $\beta 2$ subunit is able to bind to tenascins, and the $\beta 1$ subunit can bind to the cell adhesion molecules Nf186, contactin, and NrCAM (neuron-glia-related cell adhesion molecule) (Srinivasan et al., 1998; McEwen and Isom, 2004). Although the adhesive functions of the $\mathrm{Na}^{+}, \mathrm{K}^{+}$-ATPase $\beta 3$ subunit in the nervous system are currently unknown, it would be interesting to examine whether altering $\beta 3$ expression affects cellular processes such as neuronal migration and neurite outgrowth during development.

\section{References}

Antonicek H, Persohn E, Schachner M (1987) Biochemical and functional characterization of a novel neuron-glia adhesion molecule that is involved in neuronal migration. J Cell Biol 104:1587-1595.

Béguin P, Wang X, Firsov D, Puoti A, Claeys D, Horisberger JD, Geering K (1997) The $\gamma$ subunit is a specific component of the Na, K-ATPase and modulates its transport function. EMBO J 16:4250-4260.

Berridge MJ (1998) Neuronal calcium signalling. Neuron 21:13-26.

Blackshaw SE, Warner AE (1976) Alterations in resting membrane properties during neural plate stages of development of the nervous system. J Physiol 255:231-247.

Borodinsky LN, Root CM, Cronin JA, Sann SB, Gu X, Spitzer NC (2004) Activity-dependent homeostatic specification of transmitter expression in embryonic neurons. Nature 429:523-530.

Bouron A (2000) Activation of a capacitative $\mathrm{Ca}^{2+}$ entry pathway by store depletion in cultured hippocampal neurones. FEBS Lett 470:269-272.

Breckenridge LJ, Warner AE (1982) Intracellular sodium and the differentiation of amphibian embryonic neurones. J Physiol 332:393-413.

Bronchain OJ, Pollet N, Ymlahi-Ouazzani Q, Dhorne-Pollet S, Helbling JC, Lecarpentier JE, Percheron K, Wegnez M (2007) The olig family: phylogenetic analysis and early gene expression in Xenopus tropicalis. Dev Genes Evol 217:485-497.

Chemin J, Nargeot J, Lory P (2002) Neuronal T-type $\alpha 1 \mathrm{H}$ calcium channels induce neuritogenesis and expression of high-voltage-activated calcium channels in the NG108-15 cell line. J Neurosci 22:6856-6862.

Conklin MW, Lin MS, Spitzer NC (2005) Local calcium transients contribute to disappearance of pFAK, focal complex removal and deadhesion of neuronal growth cones and fibroblasts. Dev Biol 287:201-212.

Davies CS, Messenger NJ, Craig R, Warner AE (1996) Primary sequence and developmental expression pattern of mRNAs and protein for an $\alpha 1$ sub-
B

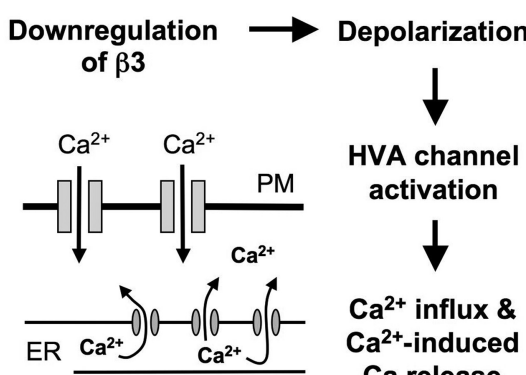

Channel insertion

Store-operated $\mathrm{Ca}^{2+}$ channels

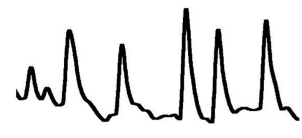

Ca release

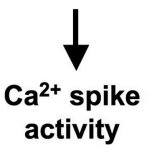

activity
Voltage-gated
channels

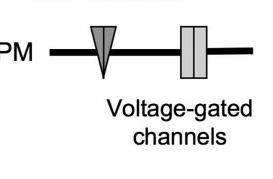

Figure 7. Model of the roles of $\beta 3$ expression during neuronal development. $\boldsymbol{A}$, Upregulation of $\beta 3$ hyperpolarizes neurons, g removal of inactivation of calcium channels and/or insertion of voltage-gated or store-operated channels into the plasma membrane (PM). $\boldsymbol{B}$, Subsequent downregulation of $\beta 3$ triggers a cascade of events necessary for $\mathrm{Ca}^{2+}$ spike production including activation of HVA current, calcium-induced calcium release, and refilling of the ER.

unit of the sodium pump cloned from the neural plate of Xenopus laevis. Dev Biol 174:431-447.

Desarmenien MG, Clendening B, Spitzer NC (1993) In vivo development of voltage-dependent ionic currents in embryonic Xenopus spinal neurons. J Neurosci 13:2575-2581.

Eid SR, Brändli AW (2001) Xenopus Na, K-ATPase: primary sequence of the $\beta 2$ subunit and in situ localization of $\alpha 1, \beta 1$, and $\gamma$ expression during pronephric kidney development. Differentiation 68:115-125.

Emptage NJ, Reid CA, Fine A (2001) Calcium stores in hippocampal synaptic boutons mediate short-term plasticity, store-operated $\mathrm{Ca}^{2+}$ entry, and spontaneous transmitter release. Neuron 29:197-208.

Feske S, Gwack Y, Prakriya M, Srikanth S, Puppel SH, Tanasa B, Hogan PG, Lewis RS, Daly M, Rao A (2006) A mutation in Orail causes immune deficiency by abrogating CRAC channel function. Nature 441:179-185.

Filippi A, Tiso N, Deflorian G, Zecchin E, Bortolussi M, Argenton F (2005) The basic helix-loop-helix olig3 establishes the neural plate boundary of the trunk and is necessary for development of the dorsal spinal cord. Proc Natl Acad Sci U S A 102:4377-4382.

Geering K (2001) The functional role of $\beta$ subunits in oligomeric P-type ATPases. J Bioenerg Biomembr 33:425-438.

Gloor S, Antonicek H, Sweadner KJ, Pagliusi S, Frank R, Moos M, Schachner M (1990) The adhesion molecule on glia (AMOG) is a homologue of the $\beta$ subunit of the Na, K-ATPase. J Cell Biol 110:165-174.

Gomez TM, Spitzer NC (1999) In vivo regulation of axon extension and pathfinding by growth-cone calcium transients. Nature 397:350-355.

Gomez TM, Robles E, Poo M, Spitzer NC (2001) Filopodial calcium transients promote substrate-dependent growth cone turning. Science 291:1983-1987.

Good PJ, Richter K, Dawid IB (1990) A nervous system-specific isotype of the $\beta$ subunit of the $\mathrm{Na}^{+}, \mathrm{K}^{+}$-ATPase expressed during early development of Xenopus laevis. Proc Natl Acad Sci U S A 87:9088-9092.

Gottmann K, Dietzel ID, Lux HD, Huck S, Rohrer H (1988) Development of inward currents in chick sensory and autonomic neuronal precursor cells in culture. J Neurosci 8:3722-3732.

Gu X, Spitzer NC (1993) Low-threshold $\mathrm{Ca}^{2+}$ current and its role in spontaneous elevations of intracellular $\mathrm{Ca}^{2+}$ in developing Xenopus neurons. J Neurosci 13:4936-4948.

$\mathrm{Gu}$ X, Spitzer NC (1995) Distinct aspects of neuronal differentiation encoded by frequency of spontaneous $\mathrm{Ca}^{2+}$ transients. Nature 375:784-787.

Gu X, Olson EC, Spitzer NC (1994) Spontaneous neuronal calcium spikes and waves during early differentiation. J Neurosci 14:6325-6335.

Hayes BP, Roberts A (1973) Synaptic junction development in the spinal cord of an amphibian embryo: an electron microscope study. Z Zellforsch Mikrosk Anat 137:251-269.

Holliday J, Spitzer NC (1990) Spontaneous calcium influx and its roles in differentiation of spinal neurons in culture. Dev Biol 141:13-23. 
Holliday J, Adams RJ, Sejnowski TJ, Spitzer NC (1991) Calcium-induced release of calcium regulates differentiation of cultured spinal neurons. Neuron 7:787-796.

Ikeda K, Onaka T, Yamakado M, Nakai J, Ishikawa TO, Taketo MM, Kawakami K (2003) Degeneration of the amygdala/piriform cortex and enhanced fear/anxiety behaviors in sodium pump $\alpha 2$ subunit (Atpla2)deficient mice. J Neurosci 23:4667-4676.

Ikeda K, Onimaru H, Yamada J, Inoue K, Ueno S, Onaka T, Toyoda H, Arata A, Ishikawa TO, Taketo MM, Fukuda A, Kawakami K (2004) Malfunction of respiratory-related neuronal activity in $\mathrm{Na}^{+}, \mathrm{K}^{+}$-ATPase $\alpha 2$ subunit-deficient mice is attributable to abnormal $\mathrm{Cl}^{-}$homeostasis in brainstem neurons. J Neurosci 24:10693-10701.

James PF, Grupp IL, Grupp G, Woo AL, Askew GR, Croyle ML, Walsh RA, Lingrel JB (1999) Identification of a specific role for the Na, K-ATPase $\alpha 2$ isoform as a regulator of calcium in the heart. Mol Cell 3:555-563.

Kaplan JH (2002) Biochemistry of Na,K-ATPase. Annu Rev Biochem 71:511-535.

Kessaris N, Pringle N, Richardson WD (2001) Ventral neurogenesis and the neuron-glial switch. Neuron 31:677-680.

Koizumi K, Higashida H, Yoo S, Islam MS, Ivanov AI, Guo V, Pozzi P, Yu SH, Rovescalli AC, Tang D, Nirenberg M (2007) RNA interference screen to identify genes required for Drosophila embryonic nervous system development. Proc Natl Acad Sci U S A 104:5626-5631.

Lavoie L, Levenson R, Martin-Vasallo P, Klip A (1997) The molar ratios of $\alpha$ and $\beta$ subunits of the $\mathrm{Na}^{+}-\mathrm{K}^{+}$-ATPase differ in distinct subcellular membranes from rat skeletal muscle. Biochemistry 36:7726-7732.

Lescale-Matys L, Putnam DS, McDonough AA (1993) $\mathrm{Na}^{+}-\mathrm{K}^{+}$-ATPase $\alpha 1$ - and $\beta 1$-subunit degradation: evidence for multiple subunit specific rates. Am J Physiol 264:C583-C590.

Lewis RS (2007) The molecular choreography of a store-operated calcium channel. Nature 446:284-287.

Lockery SR, Spitzer NC (1992) Reconstruction of action potential development from whole-cell currents of differentiating spinal neurons. J Neurosci 12:2268-2287.

Louvi A, Artavanis-Tsakonas S (2006) Notch signalling in vertebrate neural development. Nat Rev Neurosci 7:93-102.

Lu QR, Sun T, Zhu Z, Ma N, Garcia M, Stiles CD, Rowitch DH (2002) Common developmental requirement for olig function indicates a motor neuron/oligodentrocyte connection. Cell 109:75-86.

Madan P, Rose K, Watson AJ (2007) Na/K-ATPase $\beta 1$ subunit expression is required for blastocyst formation and normal assembly of trophectoderm tight junction-associated proteins. J Biol Chem 282:12127-12134.

Magyar JP, Bartsch U, Wang ZQ, Howells N, Aguzzi A, Wagner EF, Schachner M (1994) Degeneration of neural cells in the central nervous system of mice deficient in the gene for the adhesion molecule on glia, the $\beta 2$ subunit of murine Na, K-ATPase. J Cell Biol 127:835-845.

McCobb DP, Best PM, Beam KG (1989) Development alters the expression of calcium currents in chick limb motoneurons. Neuron 2:1633-1643.

McEwen DP, Isom LL (2004) Heterophilic interactions of sodium channel $\beta 1$ subunits with axonal and glial cell adhesion molecules. J Biol Chem 279:52744-52752.

Messenger EA, Warner AE (1979) The function of the sodium pump during differentiation of amphibian embryonic neurones. J Physiol 292:85-105.

Messenger NJ, Warner AE (2000) Primary neuronal differentiation in $\mathrm{Xe}$ nopus embryos is linked to the $\beta 3$ subunit of the sodium pump. Dev Biol 220:168-182.

Mircheff AK, Bowen JW, Yiu SC, McDonough AA (1992) Synthesis and translocation of $\mathrm{Na}^{+}-\mathrm{K}^{+}$-ATPase $\alpha$-and $\beta$-subunits to plasma membrane in MDCK cells. Am J Physiol 262:C470-C483.

Moseley AE, Lieske SP, Wetzel RK, James PF, He S, Shelly DA, Paul RJ, Boivin GP, Witte DP, Ramirez JM, Sweadner KJ, Lingrel JB (2003) The Na,KATPase $\alpha 2$ isoform is expressed in neurons, and its absence disrupts neuronal activity in newborn mice. J Biol Chem 278:5317-5324.

Müller-Husmann G, Gloor S, Schachner M (1993) Functional characterization of $\beta$ isoforms of murine Na,K-ATPase. J Biol Chem 268:26260-26267.
Nieuwkoop PD, Faber J (1967) Normal table of Xenopus laevis (Daudin), Ed 2. Amsterdam: North Holland.

O’Dowd DK, Ribera AB, Spitzer NC (1988) Development of voltagedependent calcium, sodium and potassium currents in Xenopus spinal neurons. J Neurosci 8:792-805.

Orlowski J, Lingrel JB (1988) Tissue-specific and developmental regulation of rat $\mathrm{Na}, \mathrm{K}-\mathrm{ATPase}$ catalytic $\alpha$ isoform and $\beta$ subunit mRNAs. J Biol Chem 263:10436-10442.

Prakriya M, Feske S, Gwack Y, Srikanth S, Rao A, Hogan PG (2006) Orail is an essential pore subunit of the CRAC channel. Nature 443:230-233.

Pu HX, Scanzano R, Blostein R (2002) Distinct regulatory effects of the Na,K-ATPase $\gamma$ subunit. J Biol Chem 277:20270-20276.

Root CM, Velázquez-Ulloa NA, Monsalve GC, Minakova E, Spitzer NC (2008) Embryonically expressed GABA and glutamate drive electrical activity regulating neurotransmitter specification. J Neurosci 28:4777-4784.

Rowe SJ, Messenger NJ, Warner AE (1993) The role of noradrenaline in the differentiation of amphibian embryonic neurons. Development 119:1343-1357.

Rowitch DH (2004) Glial specification in the vertebrate neural tube. Nat Rev Neurosci 5:409-419.

Sann SB, Xu L, Nishimune H, Sanes JR, Spitzer NC (2008) Neurite outgrowth and in vivo sensory innervation mediated by a $\mathrm{Ca}_{\mathrm{v}} 2.2$-laminin $\beta 2$ stop signal. J Neurosci 28:2366-2374.

Schubiger M, Feng Y, Fambrough DM, Palka J (1994) A mutation of the Drosophila sodium pump $\alpha$ subunit gene results in bang-sensitive paralysis. Neuron 12:373-381.

Shimojo H, Ohtsuka T, Kageyama R (2008) Oscillations in Notch signaling regulate maintenance of neural progenitors. Neuron 58:52-64.

Shoshani L, Contreras RG, Roldán ML, Moreno J, Lázaro A, Matter K, Cereijido M (2005) The polarized expression of $\mathrm{Na}^{+}, \mathrm{K}^{+}$-ATPase in epithelia depends on the association between $\beta$-subunits located in neighboring cells. Mol Bio Cell 16:1071-1081.

Soboloff J, Spassova MA, Tang XD, Hewavitharana T, Xu W, Gill DL (2006) Orail and STIM reconstitute store-operated calcium channel function. J Biol Chem 281:20661-20665.

Spitzer NC (2006) Electrical activity in early neuronal development. Nature 444:707-712.

Srinivasan J, Schachner M, Catterall WA (1998) Interaction of voltagegated sodium channels with the extracellular matrix molecules tenascin-C and tenascin-R. Proc Natl Acad Sci U S A 95:15753-15757.

Therien AG, Goldshleger R, Karlish SJ, Blostein R (1997) Tissue-specific distribution and modulatory role of the $\gamma$ subunit of the Na,K-ATPase. J Biol Chem 272:32628-32634.

Tobin V, Gouty LA, Moos FC, Desarménien MG (2006) A store-operated current (SOC) mediates oxytocin autocontrol in the developing rat hypothalamus. Eur J Neurosci 24:400-404.

Vagin O, Tokhtaeva E, Sachs G (2006) The role of the $\beta 1$ subunit of the $\mathrm{Na}, \mathrm{K}-\mathrm{ATPase}$ and its glycosylation in cell-cell adhesion. J Biol Chem 281:39573-39587.

Vig M, Peinelt C, Beck A, Koomoa DL, Rabah D, Koblan-Huberson M, Kraft S, Turner H, Fleig A, Penner R, Kinet JP (2006) CRACM1 is a plasma membrane protein essential for store-operated $\mathrm{Ca}^{2+}$ entry. Science 312:1220-1223.

Yaari Y, Hamon B, Lux HD (1987) Development of two types of calcium channels in cultured mammalian hippocampal neurons. Science 235:680-682.

Yeromin AV, Zhang SL, Jiang W, Yu Y, Safrina O, Cahalan MD (2006) Molecular identification of the CRAC channel by altered ion selectivity in a mutant of Orai. Nature 443:226-229.

Zhou Q, Anderson DJ (2002) The bHLH transcription factors OLIG2 and OLIG1 couple neuronal and glial subtype specification. Cell 109:61-73.

Zhou Q, Choi G, Anderson DJ (2001) The bHLH transcription factor Olig2 promotes oligodendrocyte differentiation in collaboration with $\mathrm{Nkx2.2}$. Neuron 31:791-807. 